\title{
Reaktif Güç Desteği için Kullanılan Üç Seviyeli H-Köprü Evirici Tabanlı D-STATKOM’un dq-Eksen Akımlarının Bulanık Oransal İntegral Denetleyici ile Denetimi
}

\author{
Hakan AÇIKGÖZ ${ }^{1 *}$, Resul ÇÖTEL $\dot{I}^{2}$ \\ ${ }^{1}$ Kilis 7 Aralık Üniversitesi, Teknik Bilimler Meslek Yüksekokulu, Elektrik-Enerji Bölümü, Kilis \\ ${ }^{2}$ Fırat Üniversitesi, Teknoloji Fakültesi, Enerji Sistemleri Mühendisliği Bölümü, Elazı̆̆ \\ ${ }^{* 1}$ hakanacikgoz@kilis.edu.tr, ${ }^{2}$ rcoteli@ firat.edu.tr
}

\begin{abstract}
Öz: Güç sistemlerinde gerilim kararlılığı ve reaktif güç kompanzasyonu en önemli problemlerden biridir. Geleneksel olarak gerilim kararlılığı ve reaktif güç kompanzasyonu için kondansatör veya endüktans grupları kullanılmaktadır. Son yıllarda, iletim ve dağıtım sistemlerinin reaktif güç kompanzasyonunda geleneksel kompanzatörlere göre cevap hızları daha iyi olan dönüştürücü tabanlı dağıtım kompanzatörleri kullanılmaktadırlar. Dağıtım Statik Senkron Kompanzatör (D-STATKOM), dağıtım sistemlerinde yaygın olarak kullanılan dönüştürücü tabanlı bir dağıtım kompanzatörüdür. Bu çalışmada, üç seviyeli Hköprü evirici tabanlı D-STATKOM'un dq-eksen akımları Bulanık Oransal + İntegral (Bulanık-PI) denetleticiyi ile denetlenmiştir. Bu amaçla, D-STATKOM’un deneysel düzeneği hazırlanmıştır. Deneysel çalışmalar için DS1103 denetleyici kart kullanılmıştır. Bulanık-PI akım denetimli D-STATKOM'un dinamik performansı bekleme durumundan kapasitif çalışma durumuna geçiş, bekleme durumundan endüktif çalışma durumuna geçiş, kapasitif çalışma durumundan endüktif çalışma durumuna geçiş ve son olarak endüktif çalışma durumundan kapasitif çalışma durumuna geçiş olmak üzere dört farklı çalışma şartı için test edilmiştir. Bu çalışma şartları altında Bulanık-PI akım denetimli D-STATKOM'un istenilen aktif (d-ekseni) ve reaktif (q-ekseni) akımı çok kısa sürede sağladığı, dq-eksen akım bileşenlerinde ve DA-hat gerilimlerinde sürekli durum hatasının olmadığı gözlemlenmiştir.
\end{abstract}

Anahtar kelimeler: Reaktif güç kompanzasyonu, D-STATKOM, dq-eksen akımı, Bulanık-PI denetleyici

\section{dq-axis Current Control of D-STATCOM Based Three Level H-Bridge Used for Reactive Power Support via Fuzzy Proportional Integral Controller}

\begin{abstract}
Voltage stability and reactive power compensation are one of the most important problems in power systems. Conventionally, capacitor or inductance groups are used for voltage stability and reactive power compensation. Recently, the converter based distribution compensators that have better response than conventional compensators have been used in reactive power compensation of transmission and distribution systems. Distribution Static Synchronous Compensator (D-STATCOM) is a widely used converter-based distribution compensator. In this study, dq-axis currents of the three-level H-bridge inverterbased D-STATCOM was controlled by Fuzzy Proportional + Integral (Fuzzy-PI) controller. For this purpose, the experimental setup of D-STATCOM was prepared. DS1 103 controller card was used for experimental studies. The dynamic performance of Fuzzy-PI current controlled D-STATCOM was investigated for four different operating conditions, transition from standby to capacitive operating state, transition from standby to inductive operating state, transition from capacitive operation to inductive operating state and finally transition from inductive to capacitive operation state. Under these operating conditions, it was observed that Fuzzy-PI current controlled D-STATCOM provides the desired active (d-axis) and reactive (q-axis) current in a very short time, and there was no continuous state error in the dq-axis current components and as well as DC-line voltages.
\end{abstract}

Key words: Reactive power compensation, D-STATCOM, dq-axis current, Fuzzy-PI controller

\section{Giriş}

Enerji sistemlerinin denetiminde en önemli problemlerden biri reaktif güç kompanzasyonudur. Reaktif güç, iletim sisteminde kayıpların artmasına, iletim hattının güç iletim kapasitesinin azalmasına ve hat sonundaki gerilimin genliğinde çok büyük değişmelere neden olur. Bu yüzden alternatif akım güç sistemlerinde iletilebilir gücü arttırmak ve kayıpları azaltmak için reaktif güç kompanzasyonu yapmak gerekir. Son yıllarda enerji iletim ve dağıtım sistemleri için hızlı kompanzasyon ihtiyacı giderek önem kazanmaktadır.

Günümüzde güç elektroniği elemanları, anahtarlama hızlarının yüksek olması nedeniyle kompanzasyon uygulamalarında tercih edilmektedirler. Güç sistemlerinde kompanzasyonunun yarı iletken anahtarlar ile yapılması durumunda, gerilim çökmelerinin önlenebileceği, geçici ve dinamik kararlı̆̆ iyileştirebileceği

\footnotetext{
* Sorumlu yazar: hakanacikgoz@kilis.edu.tr. Yazarların ORCID Numarası: ${ }^{10000-0002-6432-7243, ~}{ }^{20000-0002-7365-4318}$
} 
görülmüştür. Dağııım STATKOM’u (D-STATKOM) gerilim çökmelerini önlemek, geçici ve dinamik kararlılı̆̆ iyileştirmek için dağııım sistemlerinde kullanılan şönt bağlı evirici tabanlı bir kompanzasyon aygıtıdır [1-3].

Genel olarak D-STATKOM'un denetim yapısında referans akımı elde etmek için doğrusal denetim teknikleri kullanılarak Oransal + İntegral (PI) denetleyiciler tasarlanmaktaydı. Doğrusal denetim yöntemlerinde sistem denklemleri belli bir çalışma noktası etrafında doğrusallaş̧ııılır ve bu doğrusal denklemler yardımı ile PI denetleyici tasarlanır. Doğrusal denetim yöntemlerinde sistemin tam doğrusal matematiksel modelinin bilinmesi gerekir. Fakat sistemin tam doğrusal matematiksel modelini elde etmek zordur. Ayrıca sistemin çalışma şartları değiştiği zaman bu denetleyicilerin performanslarının kötüleşmesi önemli bir dezavantajdır. Generatör ve güç elektroniği devreleri içeren bir güç sistemi doğrusal olmayan ayrıca hatlar ve yükler sürekli olarak devreye alınıp devreden çıkarılmasından dolayı şebeke konfigürasyonu değiştiği için durağan olmayan bir sistemdir. Bu tür sistemlerin dayanıklı denetleyiciler ile denetlenmesi daha uygundur [3-8].

Klasik denetim yöntemlerine alternatif olarak, D-STATKOM'un dinamik performansını iyileştirmek için doğrusal olmayan ve uyarlanabilir denetleyici yapıları önerilmiştir. Son yıllarda, Bulanık Mantık Denetleyici (BMD) yapıları sistemin çalışma noktasının değişmesi gibi durumların üstesinden gelebilme yeteneklerinden dolayı güç sistemlerinde geleneksel denetleyicilere alternatif olarak kullanılmaya başlanmıştır. BMD'lerin sistemin tam matematiksel modeline ihtiyaç duymaması, doğrusal olmayan sistemlere uygulanabilmesi, kesin olmayan girişlerle çalışabilmesi ve geleneksel denetleyicilerden daha dayanıklı olması gibi birçok avantaja sahiptir. Literatürde D-STATKOM için birçok denetleyici yöntemi önerilmiştir. Sinirsel bulanık denetleyici yapısı D-STATKOM'un eksen akımlarının denetimi için kullanılmıştır [9-12]. Ref. [13]'de, Parçacık sürüsü optimizasyonu yöntemi ile PI denetleyici parametreleri belirlenmiş ve D-STATKOM'un DA-hat gerilimi denetlenmiştir. Ref. [14]'de, Ho denetleyici yapısı D-STATKOM'a uygulanmış ve enerji kalitesinin iyileştirilmesi amaçlanmıştır. BMD yapısı D-STATKOM'un hem DA-hat geriliminin hem de dq-eksen akımlarının denetiminde kullanılmıştır [15-18]. Ref. [19]'de PI denetleyici yapısına paralel olarak harmonik kompanzasyonu denetleyici bağlanmış ve D-STATKOM'un harmonik kompanzasyonu performansının iyileştirilmesi hedeflenmiştir. Ayrıca, D-STATKOM için geri beslemeli doğrusallaştırma yöntemleri de kullanılmışır [20-21].

Bu çalışmada, deneysel kurulumu yapılan üç seviyeli H-köprü evirici tabanlı bir D-STATKOM'un dq-eksen akımlarının denetimi Bulanık-PI denetleyici ile gerçekleştirilmiştir. Bulanık-PI akım denetimli D-STATKOM'un dinamik performansını incelemek için üç seviyeli bir H-köprü evirici tabanlı deneysel kurulum gerçekleştirilmiştir. Deneysel çalışmalar için gerçekleştirilen denetim algoritmaları dSPACE DS1103 denetleyici kartı ile sağlanmıştır. Üç seviyeli H-köprü evirici için kapı işaretleri çok seviyeli sinüzoidal darbe genişlik modülasyon (ÇS-DGM) yöntemi ile elde edilmiştir. D-STATKOM'un dq-eksen akımları iki tane Bulanık-PI denetleyici ile birbirinden bağımsız bir şekilde denetlenmiş̧ir. Ayrıca, önerilen denetleyicinin performansını değerlendirmek için dört farklı senaryo düşünülmüştür. Deneysel sonuçlardan, Bulanık-PI akım denetimli D-STATKOM'un farklı çalışma şartları altında istenilen reaktif akımı sürekli durum hatası olmadan çok kısa sürede sağladığı görülmüştür. Ayrıca, bu çalışmanın diğer kısımları şu şekilde düzenlenmiştir. Üç seviyeli D-STATKOM'un matematiksel modeli 2. Kısımda verilmiştir. 3. Kısımda, Bulanık-PI denetleyicinin özellikleri açıklanarak tasarımı hakkında bilgiler verilmiştir. Önerilen denetleyicinin performansını göstermek için deneysel kurulum 4. Kısımda gerçekleştirilmiştir. Elde edilen sonuçlar ise 5.kısımda sunulmuştur.

\section{2. Üç Seviyeli D-STATKOM'un Matematiksel Modeli}

D-STATKOM veya statik kondenser olarak bilinen ASVC (İleri Statik VAR Kompanzatör) bağlı bulunduğu güç sisteminden reaktif akım verecek/çekecek şekilde denetlenebilen, endüktans-kondansatör gibi bir enerji depolama elemanı ile üç fazlı sistem arasına bağlanan bir evirici kullanılarak yapılan şönt bağlı bir kompanzasyon aygıtıdır. Evirici tarafından üretilen çıkış geriliminin genliği D-STATKOM ile güç sistemi arasındaki reaktif güç alışverişini belirler. Eviricinin çıkış geriliminin genliği bara geriliminin genliğinden fazla ise, akım bağlantı transformatörünün kaçak reaktansı yardımı ile eviriciden baraya doğru akar ve evirici, sistem için kapasitif reaktif güç üretir. Eviricinin ürettiği çıkış geriliminin genliği bara geriliminin genliğinden küçük olması durumunda akım baradan eviriciye doğru akar ve evirici endüktif reaktif güç tüketir.

Eviricinin çıkış gerilimi ve bara geriliminin genliğinin birbirlerine eşit olduğu durumda ise herhangi bir reaktif güç alı̧̧verişi olmaz. Üç seviyeli D-STATKOM'un matematiksel modelinin elde edilmesi sistemin denetimi için önemlidir. Üç seviyeli H-köprü evirici tabanlı D-STATKOM'un yapısı Şekil 1'de verilmiştir. Şekil 1'de görüldüğü gibi, her bir H-köprü evirici bağlantı noktasına (PCC) bir bağlantı endüktansı vasıtasıyla bağlanır. 
Burada, $C$; DA-hat kapasitörünü, $L_{s}$ hat endüktansını ve $R_{s}$ ise hat endüktansının iç direncini temsil etmektedir. Şebeke ve D-STATKOM arasındaki reaktif güç alışverişi, inverter çıkış geriliminin genliğinin ayarlanmasıyla sağlanır. D-STATKOM tarafından üretilen/çekilen reaktif güç ve aktif güç aşağıdaki eşitlikle gösterilebilir:

$P=\frac{V_{s} \cdot V_{i}}{X} \sin \delta$

$Q=\frac{V_{s}}{X}\left(V_{s}-V_{i} \cos \delta\right)$

Burada, $X$; bağlantı endüktansının reaktansını, $V_{s}$; şebeke gerilimini $V_{i}$; inverter çıkış gerilimini, $\delta$ ise DSTATKOM'un temel gerilimi ile şebeke arasındaki faz farkını ifade etmektedir.

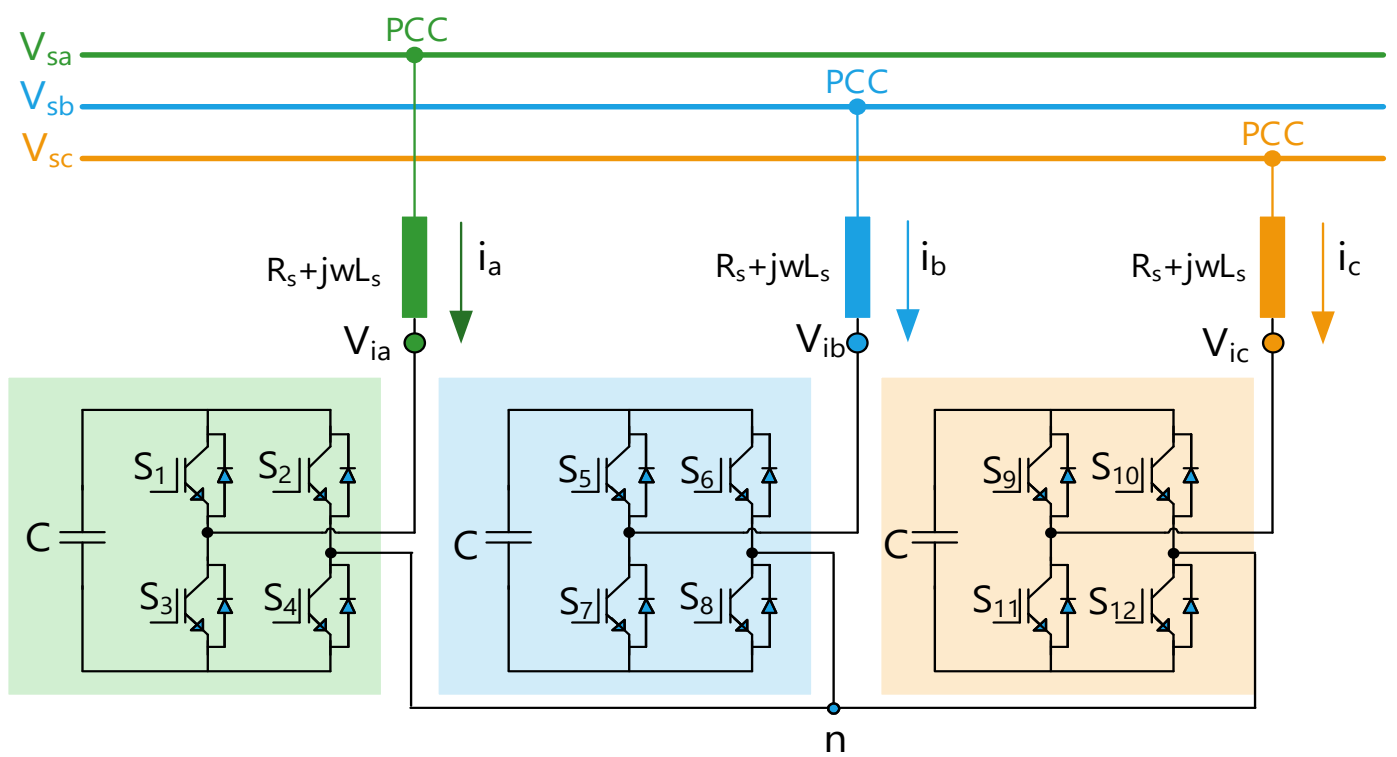

Şekil 1. Üç seviyeli D-STATKOM'un şematik gösterimi

H-köprü evirici tabanlı D-STATKOM'un şebeke tarafı $a b c$ koordinatlarında aşağıdaki gibi yazılabilir:

$\frac{d}{d t}\left[\begin{array}{c}i_{a} \\ i_{b} \\ i_{c}\end{array}\right]=-\frac{R_{s}}{L_{s}}\left[\begin{array}{c}i_{a} \\ i_{b} \\ i_{c}\end{array}\right]+\frac{1}{L_{s}}\left[\begin{array}{l}V_{s a}-V_{i a} \\ V_{s b}-V_{i b} \\ V_{s c}-V_{i c}\end{array}\right]$

Burada, şebeke ve çıkış gerilimleri sırası ile $V_{s a b c} v e V_{i a b c}$ ile gösterilmiştir. $i_{a b c}$ ise faz akımlarını ifade etmektedir. Üç fazlı sistemler genellikle $d q$-koordinat sistemine göre modellenir ve denetlenir. D-STATKOM'un şebeke tarafının $a b c$ koordinatlarındaki devre denklemi $d q$-eksenindeki değerlere dönüştürülür. Bu dönüşüm için Park dönüşüm matrisi gerekmektedir. Park dönüşüm matrisi $(K)$ aşağıdaki gibi gösterilebilir.

$K=\frac{2}{3}\left[\begin{array}{ccc}\cos \omega t & \cos (\omega t-2 \pi / 3) & \cos (\omega t+2 \pi / 3) \\ \sin \omega t & \sin (\omega t-2 \pi / 3) & \sin (\omega t+2 \pi / 3) \\ 1 / \sqrt{2} & 1 / \sqrt{2} & 1 / \sqrt{2}\end{array}\right]$

Burada, $\omega$ şebekenin açısal hızıdır. D-STATKOM'un devre denklemleri $d q$-eksen koordinatlarında aşağıdaki gibi elde edilir. 
$\frac{d}{d t}\left[\begin{array}{l}i_{d} \\ i_{q}\end{array}\right]=-\frac{R_{s}}{L_{s}}\left[\begin{array}{l}i_{d} \\ i_{q}\end{array}\right]-\omega\left[\begin{array}{l}i_{q} \\ i_{d}\end{array}\right]+\frac{1}{L_{s}}\left[\begin{array}{l}V_{s d}-V_{i d} \\ V_{s q}-V_{i q}\end{array}\right]$

Denklem 5'te, $V_{s d}$ ve $V_{s q}$; şebeke geriliminin, $V_{i d}$ ve $V_{i q}$ ise çıkış geriliminin $d q$-eksen bileşenleridir. Ayrıca, $V_{i d}$ ve $V_{i q}$ değerleri aşağıdaki denklemler ile ifade edilebilir.

$V_{i d}=M_{a} V_{d a} \cos \delta$

$V_{i q}=M_{a} V_{d a} \sin \delta$

Yukarıdaki denklemlerde, $M_{a}$ ve $V_{d a}$ sırasıyla modülasyon indeksini ve eviricinin DA-hat gerilimini ifade eder. Ayrıca, $d q$-eksenlerindeki DA-hat akımı ise aşağıdaki gibi bulunabilir.

$i_{d a}=\frac{3}{2} M_{a}\left(i_{d} \cos \delta-i_{q} \sin \delta\right)$

D-STATKOM'un dq-eksenlerindeki DA tarafının dinamik modeli ise aşağıdaki denklemle elde edilir.

$\frac{d V_{d a}}{d t}=\frac{3 M_{a}}{2 C} i_{d}\left(\cos \delta-i_{q} \sin \delta\right)$

Burada, $\delta$; evirici çıkış geriliminin temel bileşeni ile şebeke geriliminin temel bileşeni arasındaki faz farkıdır.

\section{Bulanık-PI Denetleyici}

Doğrusal denetim yöntemleri D-STATKOM'un denetiminde yaygın olarak kullanılmaktadır. Bu yöntemde sistem denklemleri belli bir çalışma noktası etrafinda doğrusallaştırılır. Doğrusal denetim yöntemleri doğrusallaştırılmış çalışma noktası etrafinda tatmin edici performansa sahiptir. Doğrusal yöntemler kullanılarak D-STATKOM için denetleyici tasarlanması ile ilgili literatürde birçok çalışma yapılmıştır. Parametre değişiminin bir sonucu olarak çalışma noktası değiştiği zaman doğrusal denetleyicilerin performansında bozulmalar olur Doğrusal yöntemlerin en büyük dezavantajı doğrusal olmayan bir sistemi doğrusallaştırma veya yüksek dereceden doğrusal olmayan bir sistemi daha düşük dereceli sisteme yaklaştırma gibi belirli varsayımların yapılarak denetleyici tasarlanmasıdır. Varsayımlarla elde edilen sistem modelleri gerçek sistemi tam olarak temsil etmeyebilir. Ayrıca sistem büyük ölçekli arızalara veya dinamik bozulmalara maruz kaldığı zaman denetlenecek olan sistemin konfigürasyonu değişir. Kısaca doğrusal denetim yöntemleri ile tasarlanan denetleyicilerin dezavantajı çalışma noktasına bağlı olmasıdır. Çalışma noktası değiştiği zaman bu denetleyicilerin performansları kötüleşir. Doğrusal denetim sistemlerinin bu gibi dezavantajından dolayı bazı araştırmacılar D-STATKOM'un denetim yapısında akıllı denetim yöntemleri önermişlerdir [16-17].

BMD’lerin diğer doğrusal olmayan denetim yöntemlerine göre en büyük avantajı sistemin matematiksel modeline ihtiyaç duymamasıdır. BMD fikri ilk olarak 1965 yılında L. Zadeh tarafından ortaya atıldı [22]. O tarihten sonra önemi gittikçe artarak günümüze kadar gelen bulanık mantık, belirsizliklerin anlatımı ve belirsizliklerle çalışılabilmesi için kurulmuş katı bir matematik düzen olarak tanımlanabilir. Günümüzde birçok uygulamada kendine yer bulan BMD'ler oldukça iyi performans gösterebilme yeteneğine de sahiptir [23-25]. Bulanık mantık ile klasik mantık arasındaki temel fark klasik mantığın önermelerin sadece aşırı uç değerleri kullanmasıdır. Klasik mantıkta bir eleman bir kümenin elemanıdır ya da değildir. Klasik mantık yöntemleriyle karmaşık sistemleri modellemek ve denetlemek bu yüzden zordur. Çünkü veriler tam ve net olmalıdır. Bulanık mantık kişiyi bu zorunluluktan kurtarır ve daha niteliksel bir tanımlama olanağı sağlar. Bir BMD, EĞER-O HALDE kurallarından oluşan bilgi tabanıdır ve bu kurallar o konuda uzman bir kişiden elde edilir. BMD'de uzman bir kişinin görüşü denetleyicinin içine gömülür yani bulanık denetleyici uzman kişinin görüşlerine göre sistemi denetler. Şekil 2'de şematik diyagramı gösterilen BMD dört ana kısımdan oluşur. Bunlar, bilgi tabanı (veri ve kural tabanı), bulanıklaştırma birimi, çıkarım mekanizması ve durulaştırma bölümleridir. 


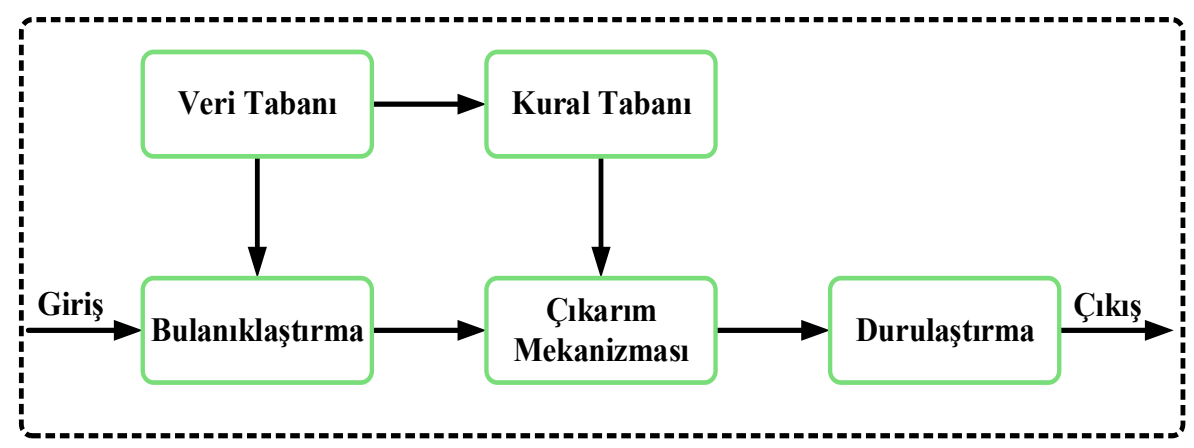

Şekil 2. BMD’nin şematik gösterimi.

Bulanıklaştırma biriminde gözlemlenmiş bir giriş alanından evrensel bir kümedeki bir grup haline getirme olarak ifade edilebilir ve BMD’nin ilk aşamasıdır. Bulanıklaştırma işlemi ile sistemden alınan giriş bilgileri dilsel niteleyicilere dönüştürülür. Bilgi tabanı BMD’nin kalbidir. Bilgi tabanı veri ve kural tabanı olmak üzere iki bölümden oluşur. Veri tabanı sistemin davranışı ve dinamikleri hakkında bilgiyi içerir ve bir uzman kişiden elde edilir. Kural tabanı bilgi tabanındaki girişleri çıkış değişkenlerine bağlayan ve mantıksal EĞER-O HALDE şeklinde yazılabilen bütün kuralları içerir. Bu kuralların yazılmasında sadece girdi verileri ile çıktı verileri arasında olabilecek tüm bağlantılar düşünülür. Böylece her bir kural girdi uzayının bir parçasını çıktı uzayına mantıksal olarak bağlar. Bulanık model olarak da bilinen çıkarım mekanizması matematiksel olarak makul bir çıkış elde etmek için kural tabanındaki kurallara bulanık nedenleri uygular. Mamdani, Takagi-Sugeno ve Tsukamoto bulanık sistemleri en çok kullanılan bulanık çıkarım mekanizmalarıdır. Mamdani yöntemi durağan sistemler (yavaş değişen dinamikli) için, Takagi-Sugeno yöntemi ise dinamik sistemler (hızlı değişen dinamikli) için daha uygundur. Durulaştırma, çıkarım mekanizmasının bulanık küme çıkışları üzerinde ölçek değişikliği yaparak gerçek sayılara dönüştüren birimdir. Maksimum, maksimumun ortalaması (MO) ve merkezlerin ağırlıklı ortalaması (MAO) gibi yöntemler durulaştırma için kullanılabilir. MAO'nun sürekli durum performansı daha iyi olmasına rağmen MO daha iyi bir geçici durum performansına sahiptir. Genellikle MAO'da daha az ortalama karesel hata meydana gelir. BMD'ye uygulanılan keskin girişin tipine bağlı olarak (hata, hatanın türevi, hatanın integrali) bulanık denetleyici doğrusal olmayan oransal, türev veya integral denetleyici olarak çalışabilir. Genelde BMD, değişken kazançlı doğrusal olmayan bir denetleyici olarak görülebilir ve bu denetleyiciler bir grup keskin girişlerden bir bulanık kümeye doğrusal olmayan bir eşleştirme sağlar Böylece daha dayanıklı, daha kompakt ve daha basit bir denetleyici tasarlanmasına izin verir. BMD, sezgisel ve matematiksel bilginin her ikisinin kullanılması ile doğrusal ve doğrusal olmayan denetleyici tasarlamak için uygun bir yöntem sağladığı için farklı denetim uygulamaları için geleneksel denetim yöntemlerine pratik olarak bir alternatif olarak günümüzde farklı birçok sistemin denetiminde kullanılmış ve başarılı sonuçlar elde edilmiştir. Bu çalışmada D-STATKOM'un denetiminde kullanılan Bulanık-PI denetleyici yapısı Şekil 3'de gösterilmiştir [26].

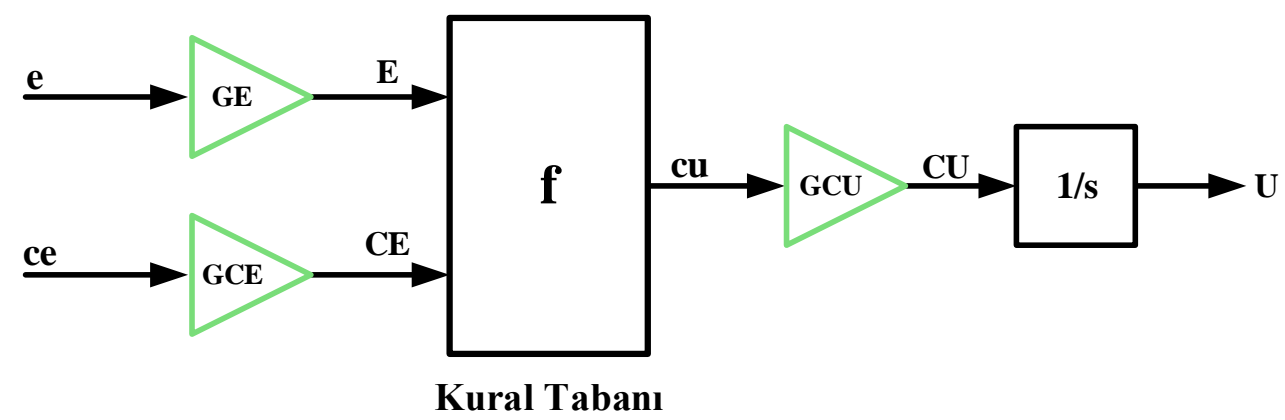

Şekil 3. Bulanık-PI denetleyici yapısı

Önerilen denetleyici yapısının çıkış sinyali aşağıdaki gibi ifade edilebilir.

$U_{n}=\sum_{i}\left(c u_{i} * G C U * T_{s}\right)$

Burada, $T_{s}$ örnekleme frekansıdır. Denetleyici çıkışı için doğrusal yaklaşım uygulanırsa; 


$$
\begin{aligned}
U_{n} & =\sum_{i=1}^{n}\left(E_{i}+C E_{i}\right) * G C U * T_{s} \\
& =G C U * \sum_{i=1}^{n}\left[G E * e_{i}+G C E * \frac{e_{i}-e_{i-1}}{T_{s}}\right] * T_{s} \\
& =G C E * G C U *\left[\frac{G E}{G C E} \sum_{i=1}^{n} e_{i}^{*} T_{s}+e_{n}\right]
\end{aligned}
$$

olarak elde edilir. Bulanık-PI denetleyicinin kazançları için aşağıdaki gibi verilebilir.

$$
G C E^{*} G C U=K_{p}
$$

$$
\frac{G E}{G C E}=\frac{1}{T_{i}}
$$

Burada, $K_{p}$ oransal kazanç ve $T_{i}$ ise integral zaman sabitidir. D-STATKOM'un denetim bloğu Şekil 4'te gösterilmiştir. Ölçülen üç faz gerilimleri ve akımları birim değere çevrilir. Gerilimler gerilim senkronizasyonu bloğuna (PLL) girilerek gerilimin açısal hızı elde edilir. PLL'den elde edilen bilgiler kullanılarak akımlar aktif ve reaktif bileşenlerine $\left(i_{d}\right.$ ve $i_{q}$ ) ayrılır. Elde edilen $i_{d}$ ve $i_{q}$ akımları Bulanık-PI denetleyicilere giriş olarak uygulanmaktadır.

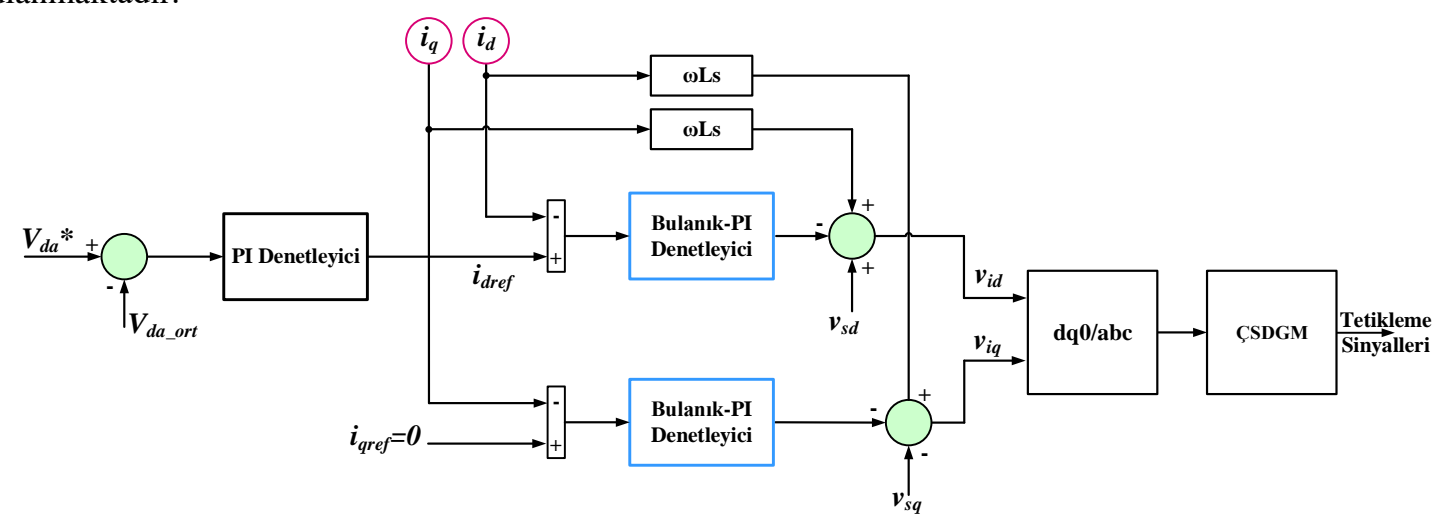

Şekil 4. D-STATKOM’un denetim bloğu

Şekil 4'te görüleceği gibi $d q$-eksen akımlarının denetimi için Bulanık-PI denetleyiciler kullanılmıştır. Bulanık-PI denetleyicilere girişler, $d q$-eksen akımlarının hatası (e) ve akım hatasının değişimi (de) alınmıştır. Denetim yapısında kullanılan Bulanık-PI denetleyicilerin giriş ve çıkışları için seçilen Üçgen üyelik fonksiyonları Şekil 5'de gösterilmiştir. Bulanık-PI denetleyicilerin girişleri ve çıkışı için 3 adet üyelik fonksiyonu kullanılmıştır. Bunlar N (Negatif), S (Sifir), P (Pozitif)'tir.

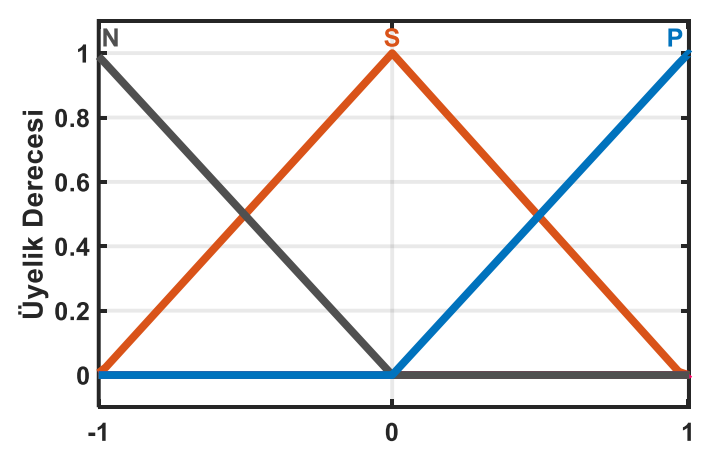

Şekil 5. Bulanık-PI denetleyicinin girişleri ve çıkışı için kullanılan üçgen üyelik fonksiyonu 
Bulanık-PI denetleyicilerin giriş ile çıkışlarını birbirine bağlayan kural tablosu ise Tablo 1'de verilmiştir.

Tablo 1. Bulanık-PI için kural tablosu

\begin{tabular}{|c|c|c|c|}
\hline $\mathbf{d e}$ & $\mathbf{N}$ & $\mathbf{S}$ & $\mathbf{P}$ \\
\hline $\mathbf{N}$ & $\mathrm{N}$ & $\mathrm{N}$ & $\mathrm{S}$ \\
\hline $\mathbf{S}$ & $\mathrm{N}$ & $\mathrm{S}$ & $\mathrm{P}$ \\
\hline $\mathbf{P}$ & $\mathrm{S}$ & $\mathrm{P}$ & $\mathrm{P}$ \\
\hline
\end{tabular}

\section{Deneysel Kurulum ve Elde Edilen Sonuçlar}

Bu çalışmada D-STATKOM'un $d q$-eksen akımları Mamdani tip Bulanık-PI denetleyici ile denetlenmiştir. Her iki eksen akımının denetimi için kullanılan Bulanık-PI denetleyiciler özdeş olup, bu denetleyicilerin girişleri ilgili akım hataları ve bu hatalardaki değişimler olarak seçilmiştir. Bulanık-PI denetleyicilerin girişleri ve çıkışları için üç üyelik fonksiyonu kullanılmıştır. Matlab/Simulink ortamı kullanılarak D-STATKOM'un deneysel çalışmaları için gerçek zamanlı bir arayüz (RTI) modeli hazırlanmış ve bu model DS1103 denetleyici kartına yüklenmiştir. Şekil 6’da D-STATKOM'un Matlab/Simulink RTI modeli verilmiştir.

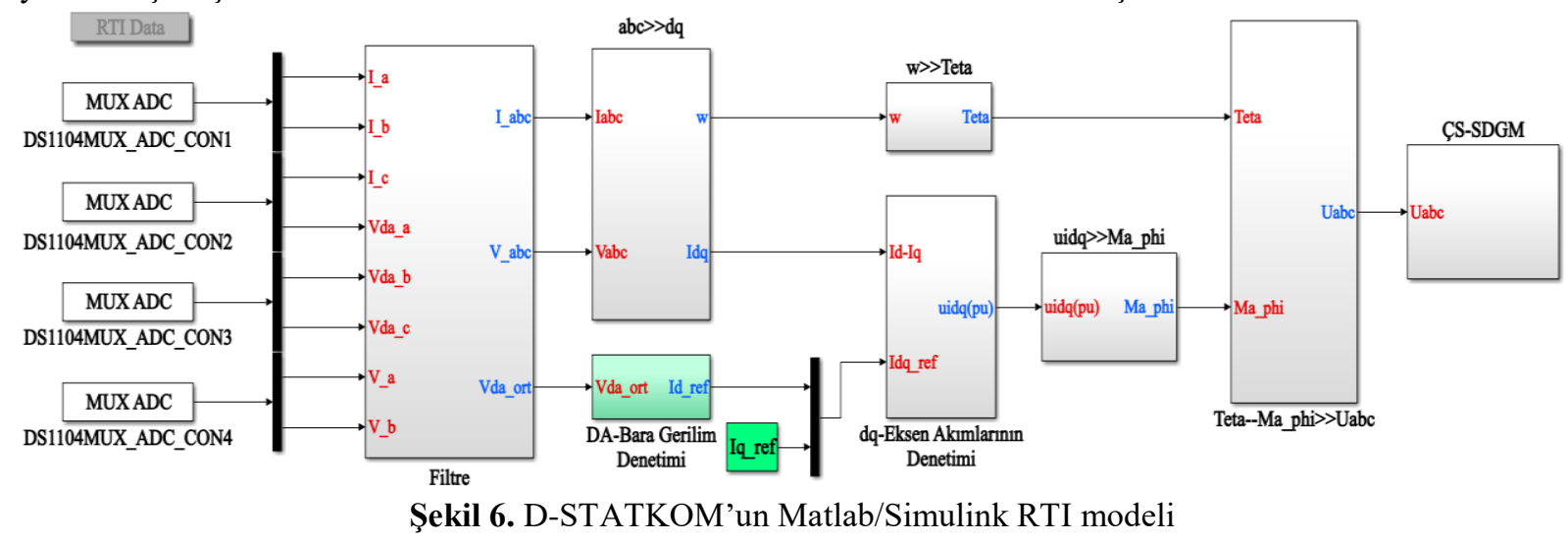

Ayrıca, D-STATKOM'un deneysel kurulum fotoğrafı Şekil 7'de gösterilmiştir. Deneysel kurulum dört kısımdan meydana gelmektedir. Bunlar; güç devresi, DS1103 denetleyici kartı, ölçüm-koruma devreleri ve kap1 sürme devresidir. D-STATKOM'un güç devresi, her fazda bir adet tam köprü evirici olmak üzere üç fazlı H-köprü evirici ile oluşturulmuştur. Bu tam köprü eviriciler PM75CLA120 akıllı güç modülleri ile gerçekleştirilmiştir. Evirici anahtarları için anahtarlama işaretleri $1.25 \mathrm{kHz}$ 'lik anahtarlama frekansında ÇS-SDGM yöntemi ile üretilmiştir. Denetim amacı için gerekli olan D-STATKOM'un çıkış akımları ve D-STATKOM'un bağlı olduğu AA şebeke gerilimleri sırası ile Hall etkili LA50-S/SP1 akım ve LV25-1000 gerilim algılayıcıları ile ölçülmüştür. D-STATKOM'un gerçek zamanlı denetimi için dSPACE DS1103 denetleyici kartı kullanılmıştır. Deneysel çalışma şartlarına ilişkin parametreler Tablo 2'de verilmiştir.

Tablo 2. Deneysel kurulum ile ilgili devre parametreleri

\begin{tabular}{|c|c|}
\hline Parametre & Değer \\
\hline Hat gerilimi & $173 \mathrm{~V}, 50 \mathrm{~Hz}$ \\
\hline Bağlantı endüktansı & $2.89 \mathrm{mH}$ \\
\hline Şarj direnci & $1 \mathrm{k} \Omega / 100 \mathrm{~W}$ \\
\hline DA-hat kondansatörü & $3.3 \mathrm{mF} / 400 \mathrm{~V}$ \\
\hline Deşarj direnci & $23.5 \mathrm{k} \Omega / 5 \mathrm{~W}$ \\
\hline Anahtarlama frekansı & $2.5 \mathrm{kHz}$ \\
\hline IGBT Ölü zaman & $4.5 \mu \mathrm{s}$ \\
\hline Referans DA-hat & $170.4 \mathrm{~V}$ \\
\hline
\end{tabular}




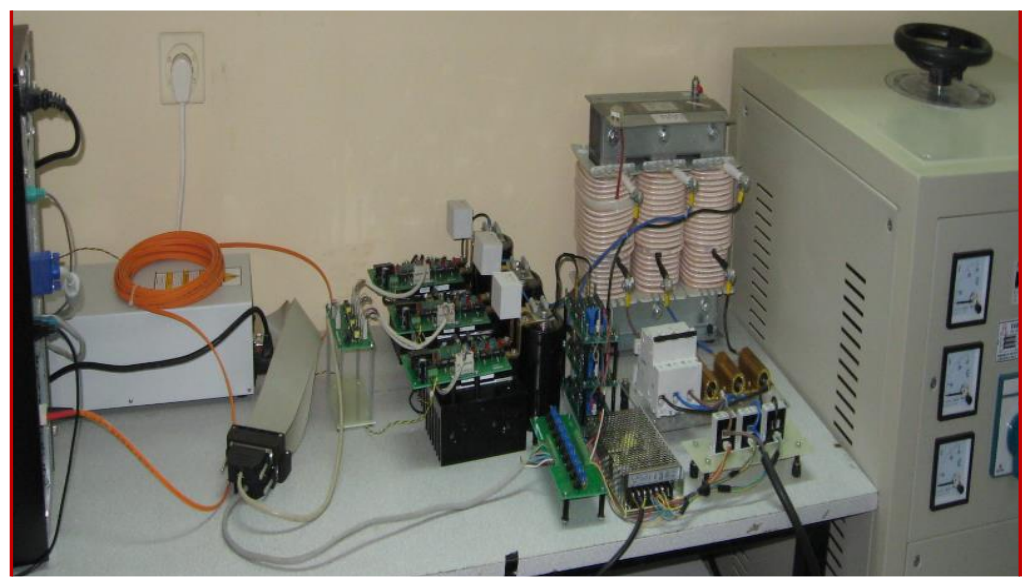

Şekil 7. D-STATKOM’un deneysel kurulumu

Evirici anahtarlarına kapı işaretleri uygulanmadan önce AA şebeke gerilimi bir varyak yardımı ile 173 V'ye ayarlanmış ve DA-hat kondansatörleri şebeke üzerinden şarj dirençleri yardımı ile doldurulmuştur. Böylece başlangıçta D-STATKOM'un yüksek akım çekmesi önlenmiştir. Kondansatörler tam doldurulduktan sonra şarj dirençleri anahtarlar yardımı ile devre dışı bırakılmış ve D-STATKOM başlatılmaya hazır hale getirilmişstir. Bulanık-PI denetimli D-STATKOM'un geçici ve sürekli durum performansı dört farklı yük şartı için incelenmiştir. $\mathrm{Bu}$ amaçla D-STATKOM'un referans reaktif akım bileşeni 0 A 'dan 16 A'ya (bekleme durumundan kapasitif çalışmaya geçiş), 0 A'dan -16 A'ya (bekleme durumundan endüktif çalışmaya geçiş), 16 A'dan -16 A'ya (kapasitif çalışmadan endüktif çalışmaya geçiş) ve -16 A'dan 16 A'ya (endüktif çalışmadan kapasitif çalışmaya geçiş) değiştirilmiştir. $\mathrm{Bu}$ şartlar altında D-STATKOM'un şebekede meydana gelebilecek bu anlık reaktif akım değişimlerinde hem talep edilen reaktif akımı sağlayabilme yeteneği hem de bu akımı ne kadar sürede sağladığı gözlemlenmiştir.

Şekil 8a-f'de sırası ile bekleme durumundan kapasitif çalışma durumuna geçiş için D-STATKOM'un reaktif akımı ve onun detay gösterimi, DA-hat kondansatör gerilimleri, modülasyon indeksinin değişimi, birim değer cinsinden a-fazı akımı-gerilimi ve şebeke gerilimi ile D-STATKOM'un gerilimi arasındaki faz açısının değişimine ait deneysel sonuçlar verilmiştir. Şekil $8 \mathrm{a}$ ve b'den görüldüğü gibi, D-STATKOM tarafından üretilen reaktif akımda sürekli durum hatasının bulunmadığı ve yerleşme süresinin yaklaşık $14.6 \mathrm{~ms}$ olduğu görülmektedir. Şebeke frekansının $50 \mathrm{~Hz}$ olduğu düşünülürse D-STATKOM bir periyottan daha kısa sürede şebekede meydana gelen değişmeye cevap verdiği görülmektedir. Şekil 8c'de DA-hat gerilimlerinin referans değerinde olduğu ancak DA-hat gerilimlerindeki dalgalanmaların kapasitif çalışma durumunda bekleme durumuna göre daha yüksek olduğu görülmektedir. Bunun nedeni evirici anahtarlarının kapasitif çalışma durumunda endüktif çalışma durumuna göre kapalı kalma sürelerinin daha uzun olmasıdır. Ayrıca modülasyon indeksi bekleme durumunda yaklaşık 0.83 iken 16 A kapasitif akım sağlama durumunda ise yaklaşık 0.93'e yükseldiği Şekil 8d'de görülmektedir. Şekil 8e'de görüleceği gibi, 0.73 s'ye kadar D-STATKOM bekleme durumunda (D-STATKOM'un akımı sıfır), 0.73 s'den sonra ise D-STATKOM kapasitif akım sağlamaya başlamıştır (a-fazı akımı gerilimine göre yaklaşık $90^{\circ}$ ileridedir). Şekil 8f'de şebeke gerilimi ile D-STATKOM'un gerilimi arasındaki faz açısının bekleme durumundan kapasitif çalışmaya geçiş durumunda azaldığı görülmektedir. Bu durum DA-hat kondansatör gerilimlerinin sabit kalmasını sağlamaktadır.

Şekil 9a-f'de sırası ile bekleme durumundan endüktif çalışma durumuna geçiş için D-STATKOM'un reaktif akımı ve onun detay gösterimi, DA-hat kondansatör gerilimleri, modülasyon indeksinin değişimi, birim değer cinsinden a-fazı akımı-gerilimi ve şebeke gerilimi ile D-STATKOM'un gerilimi arasındaki faz açısının değişimine ait deneysel sonuçlar verilmiştir. Şekil 9a ve b'den görüldüğ̈̈ gibi, hem D-STATKOM tarafından sağlanan endüktif reaktif akım referans değerini izlemekte (sürekli durum hatası yok) hem de D-STATKOM istenilen reaktif akımı çok kısa sürede sağlamaktadır (yerleşme süresi yaklaşık olarak $15 \mathrm{~ms}$ ). Şekil 9c'de verilen DA-hat gerilimlerine ilişkin deneysel sonuçlar incelendiği zaman DA-hat gerilimleri referans değerlerinde olduğu görülmektedir. Bekleme durumundan endüktif çalışmaya geçişte modülasyon indeksi bekleme durumunda yaklaşık 0.83 iken 16 A endüktif akım sağlarken ise yaklaşık 0.69'a azaldığı Şekil 9d'de görülmektedir. 0.75 s'ye kadar D-STATKOM bekleme durumunda ve akımı sıfır, 0.75 s'den sonra ise D-STATKOM endüktif akım sağlamaya başlamıştır (a-fazı akımı gerilimine göre yaklaşık $90^{\circ}$ geridedir) ve bu durum Şekil 9e'de verilmiştir. 
Şekil 9f'de ise şebeke gerilimi ile D-STATKOM'un gerilimi arasındaki faz açısının bekleme durumundan endüktif çalışmaya geçiş durumunda DA-hat kondansatör gerilimlerinin sabit kalmasını için arttı̆̆ı görülmektedir.
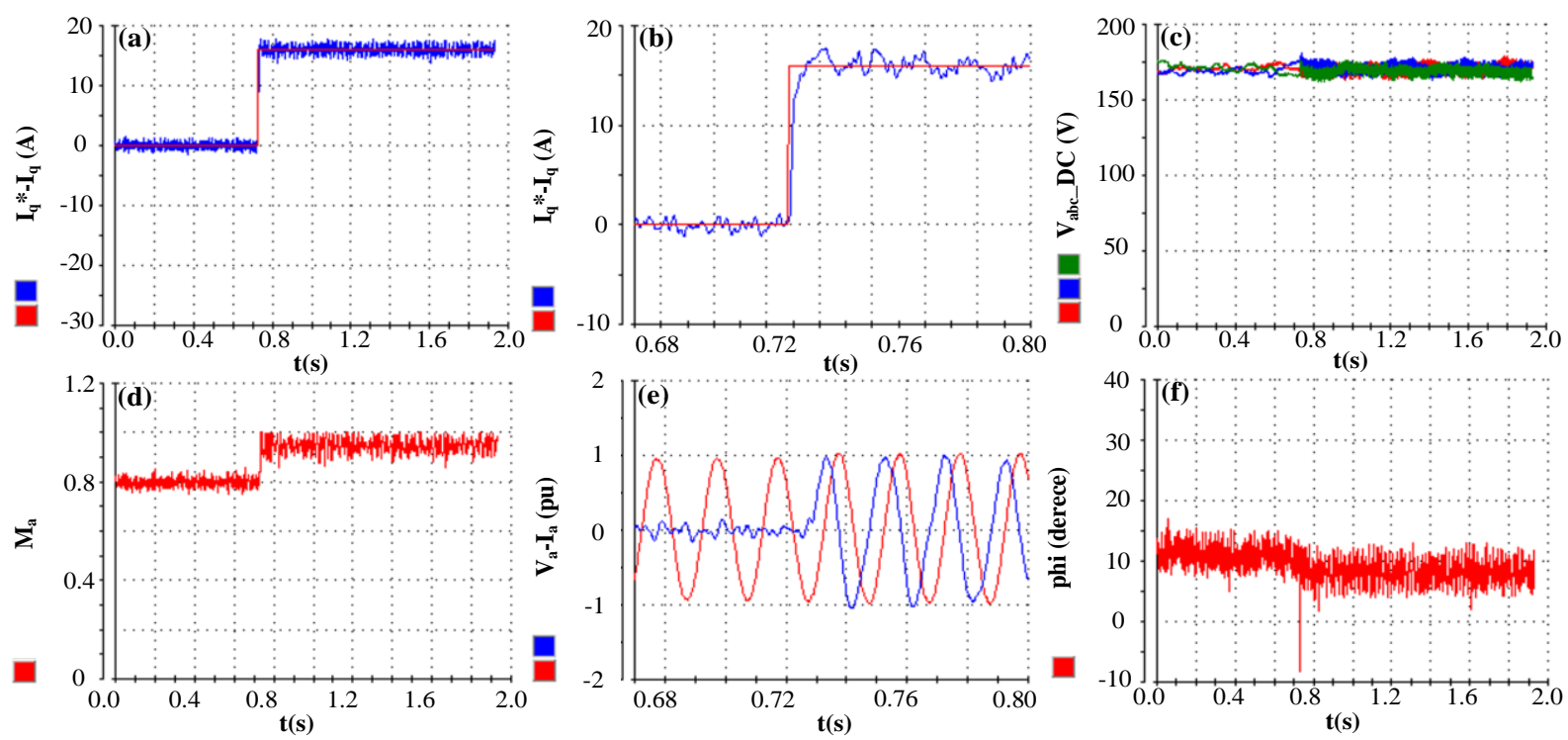

Şekil 8. Bekleme durumundan kapasitif çalışma durumuna geçiş için deneysel sonuçlar
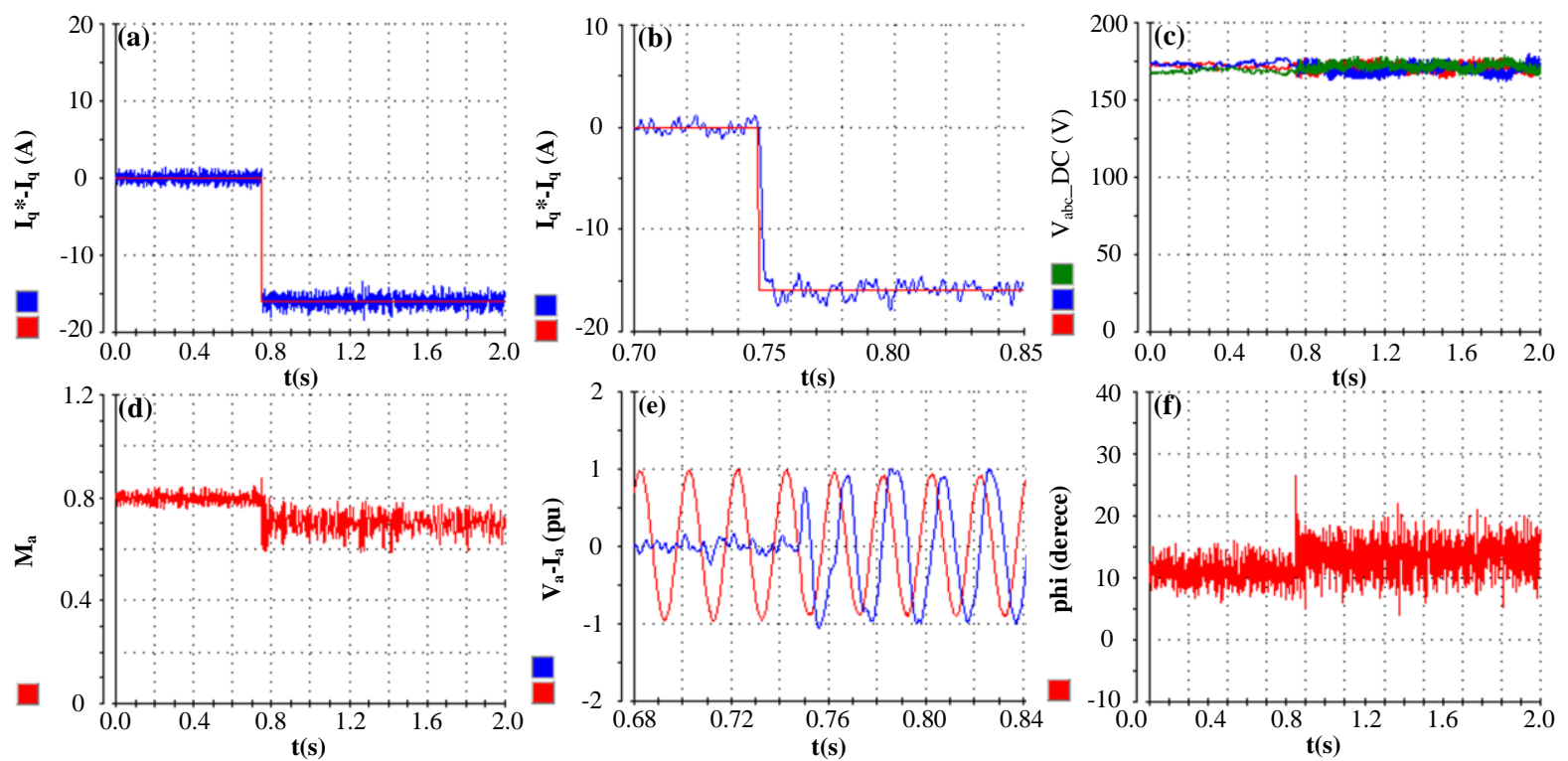

Şekil 9. Bekleme durumundan endüktif çalışma durumuna geçiş için deneysel sonuçlar

Şekil 10a-f'de sırası ile DSTATKOM'un reaktif akımı ve bu akımın detay gösterimi, DA-hat kondansatör gerilimleri, modülasyon indeksinin değişimi, birim değer cinsinden a-fazı akım-gerilimi ve AA şebeke gerilimi ile D-STATKOM'un gerilimi arasındaki faz açısının değişimini ile ilgili deneysel sonuçlar kapasitif çalışma durumundan endüktif çalışma durumuna geçiş için verilmiştir. Bu deneysel senaryoda, yaklaşık 0.47 s'ye kadar D-STATKOM'un referans reaktif akımı 16 A kapasitif, 0.47 s'den sonra ise 16 A endüktif olarak belirlenmiştir. Her iki çalışma durumunda da D-STATKOM'un reaktif akımının referans değerini izlediği Şekil 10a ve b'de görülmektedir. Ayrıca D-STATKOM istenilen reaktif akımı 29 ms gibi çok kısa sürede sağlamıştır. Şekil 10c'de ise DA-hat gerilimlerine ilişkin deneysel sonuçlar verilmiştir. Şekilden, DA-hat gerilimlerinin referans değerinde olduğu ancak kapasitif çalışma durumunda DA-hat gerilimlerindeki dalgalanmanın yukarıda bahsedilen sebepten dolayı endüktif çalışma durumuna göre daha yüksek olduğu görülmektedir. Kapasitif çalışma durumundan endüktif çalışma durumuna geçişte modülasyon indeksi yaklaşık 0.93 'ten 0.69 'a azaldığı Şekil 10d'de 
görülmektedir. Ayrıca Şekil 10e'de gösterildiği gibi, 0.47 s'ye kadar D-STATKOM kapasitif akım, bu zamandan sonra ise endüktif akım sağlamaya başlamıştır (0.47 s'ye kadar a-fazı akımı gerilimine göre yaklaşık $90^{\circ}$ ileride iken 0.47 s'den sonra a-fazı akımı gerilimine göre yaklaşık $90^{\circ}$ geridedir). Şekil 10f'de şebeke gerilimi ile DSTATKOM'un gerilimi arasındaki faz açısının kapasitif çalışma durumunda yaklaşık $9^{\circ}$, endüktif çalışma durumuna geçişte ise artarak $14^{\circ}$ yükseldiği gözlemlenmiştir. Böylece, bu geçiş esnasında DA-hat kondansatör gerilimlerinin sabit kalması sağlanmıştır.
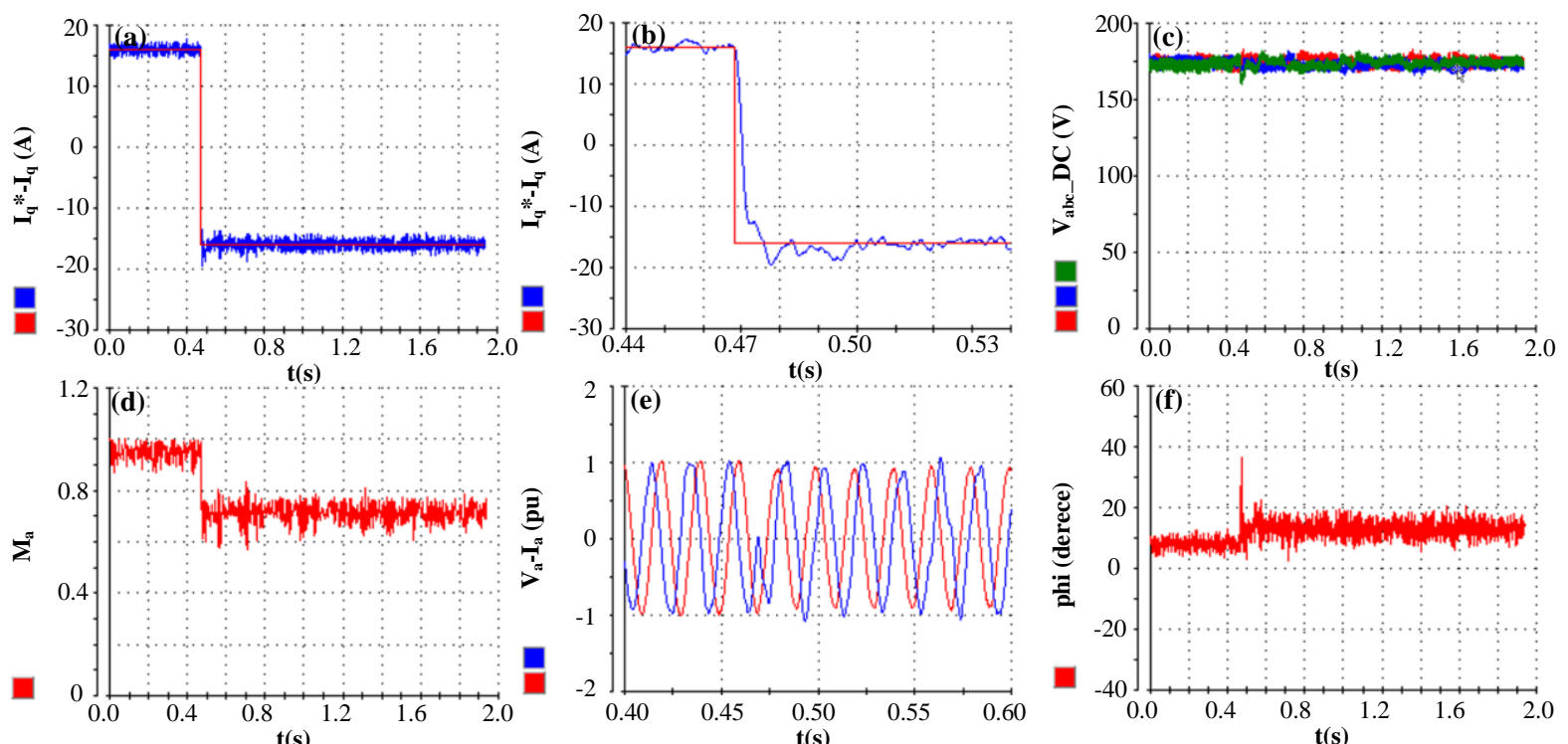

Şekil 10. Kapasitif çalışmadan endüktif çalışma durumuna geçiş için deneysel sonuçlar
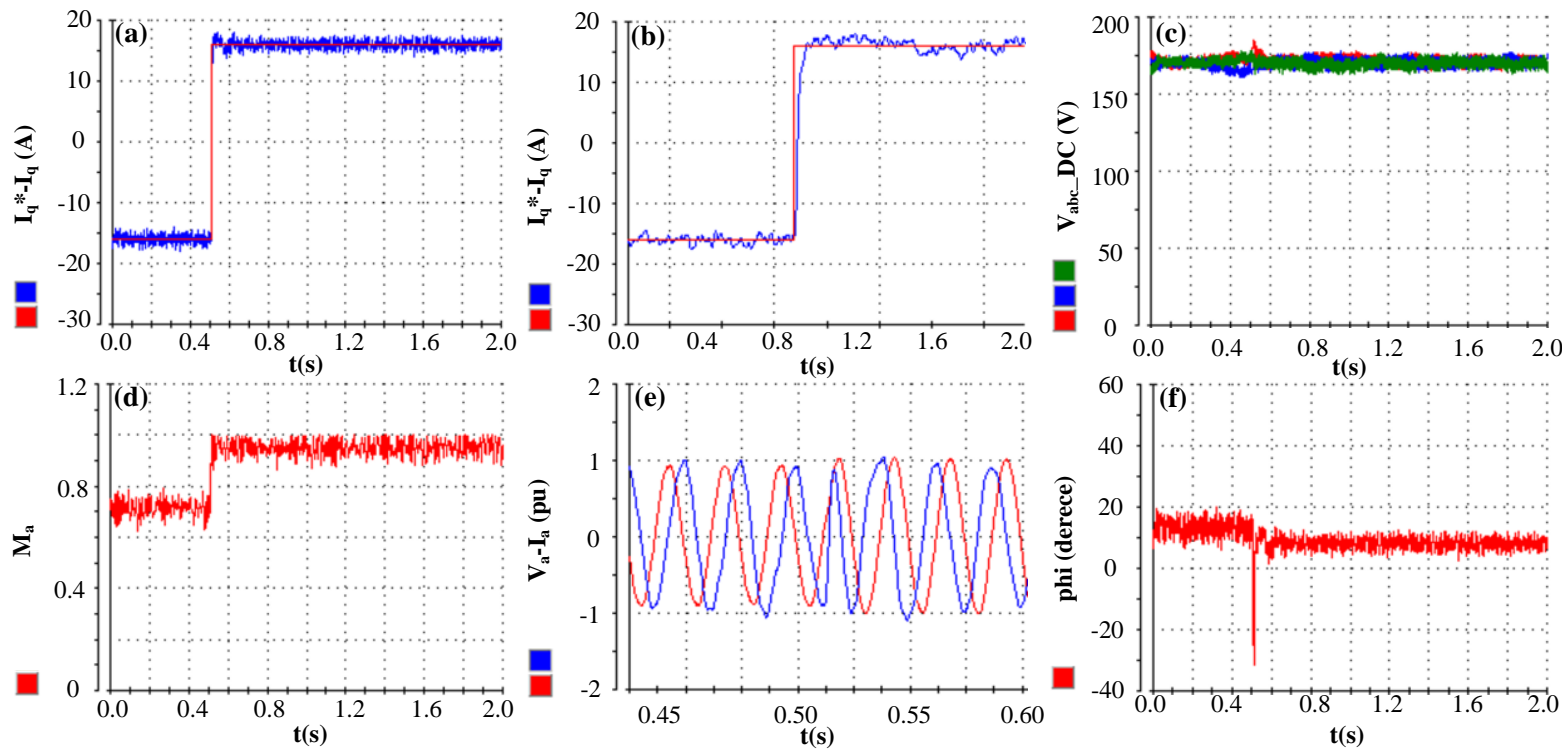

Şekil 11. Endüktif çalışma durumundan kapasitif çalışma durumuna geçiş için deneysel sonuçlar

Şekil 11a-f'de ise sırası ile endüktif çalışma durumundan kapasitif çalışma durumuna geçişte elde edilen deneysel sonuçlar verilmiştir. Bu deneysel senaryoda, 0.49 s'ye kadar D-STATKOM'un referans reaktif akımı 16 A endüktif, 0.47 s'den sonra ise 16 A kapasitif olarak belirlenmiştir. Her iki çalışma durumunda da DSTATKOM'un reaktif akımının referans değerini izlediği ve 31 ms'de istenilen reaktif akımı sağladığı Şekil 11a ve b'de görülmektedir. Şekil 11c'de ise DA-hat gerilimlerine ilişkin deneysel sonuçlar verilmiştir. Bu deneysel sonuç incelendiği zaman DA-hat gerilimlerinin referans değerinde olduğu görülmektedir. Bu çalışma koşulunda modülasyon indeksinin değişimi Şekil 11d'de verilmiştir. Endüktif çalışma durumundan kapasitif çalışma 
durumuna geçişte modülasyon indeksi yaklaşık 0.69 'dan 0.93 'e yükselmiştir. Şekil 11 e'de görüldüğü gibi, 0.49 s'ye kadar D-STATKOM endüktif akım, bu zamandan sonra ise kapasitif akım sağlamaya başlamıştır (0.49 s'ye kadar a-fazı akımı gerilimine göre yaklaşık $90^{\circ}$ geride iken 0.47 s'den sonra a-fazı akımı gerilimine göre yaklaşı $90^{\circ}$ ileridedir). Şekil $11 \mathrm{f}^{\prime}$ de şebeke gerilimi ile D-STATKOM'un gerilimi arasındaki faz açısının endüktif çalışma durumunda yaklaşı $14^{\circ}$, kapasitif çalışma durumuna geçişte ise azalarak $9^{\circ}$ yükseldiği gözlemlenmektedir.

\section{Sonuçlar}

Enerji sistemlerinin denetiminde en önemli problemlerden biri reaktif güç kompanzasyonudur. Bu çalışmada, Bulanık-PI akım denetimli üç seviyeli H-köprü evirici tabanlı bir D-STATKOM'un deneysel kurulumu gerçekleştirilmiş ve D-STATKOM şebekeye reaktif güç sağlayacak şekilde denetlenmiş̧ir. D-STATKOM'un aktif ve reaktif gücü $d q$-eksen akımlarının denetimi ile gerçekleştirilmiştir. Denetim amacı için DS1103 denetleyici kartı kullanılmıştır. Bulanık-PI akım denetimli D-STATKOM'un reaktif akım sağlayabilme yeteneği farklı yük şartları için incelenmiştir. Elde edilen deneysel sonuçlardan Bulanık-PI denetimli D-STATKOM'un sistemde meydana yük veya gerilim değişmeleri sonucunda sağlanması gereken reaktif akımı hızlı ve hatasız bir şekilde sağladığı görülmüştür.

\section{Teşekkür}

Bu çalışma, TÜBITTAK tarafindan 107E245 no.lu proje kapsamında desteklenmiştir. Yazarlar, sağlanan destekten dolayı TÜBİTAK'a teşekkür eder.

\section{Kaynaklar}

[1] Singh B, Saha R, Chandra A, Al-Haddad K. Static synchronous compensators (STATCOM): a review. IET Power Electron, 2008; 2:297-324.

[2] Singh B, Jayaprakash P, Kothari DP, Chandra A, Al-Haddad K. Comprehensive study of D-STATCOM configurations IEEE Trans Ind Informat, 2014; 10(2): 854-870.

[3] Cetin A, Ermis M. VSC-Based D-STATCOM With Selective Harmonic Elimination. IEEE Trans Ind Appl, 2009;45(3): 1000-1015.

[4] Deniz E, Coteli R, Dandil B, Tuncer S. Design and implementation of three level H-bridge inverter based D-STATCOM. Journal of Faculty of Engineering and Architecture of Gazi University, 2011;26(2): 289-298.

[5] Kumar P, Kumar N, Akella AK. A simulation based case study for control of D-STATCOM. ISA Trans, 2014;53(3): 767775 .

[6] Singh B, Kumar S, Sabha D, Arya R. An improved control algorithm of D-STATCOM for power quality improvement. Int J Electr Power Energy Syst, 2015;64: 493-504.

[7] Rahim AHMA, Nowicki EP, Bakhashwain JM. Fuzzy STATCOM Control Strategies for Power System Stabilization, ACSE Journal, 2006;6(2): 1-9.

[8] Hosseini SH, Rahnavard R, Ebrahimi Y. Reactive Power Compensation in Distribution Networks with STATCOM by Fuzzy Logic Theory. In: IEEE 2006 Power Electronics and Motion Control Conference, 14-16 Aug. 2006; Shanghai, China: IEEE. pp. 1-5.

[9] Ahmad MT, Narendra K, Bhim S. Generalised neural network-based control algorithm for DSTATCOM in distribution systems. IET Power Electron 2017;10: 1529-1538.

[10] Jayachandran J, Sachithanandam RM. Neural network-based control algorithm for DSTATCOM under nonideal source voltage and varying load conditions. Can J Elect Comput E, 2015; 38: 307-317.

[11] Coteli R, Acikgoz H, Dandil B, Tuncer S. Real-time implementation of three-level inverter-based D-STATCOM using neuro-fuzzy controller, Turkish Journal of Electrical Engineering \& Computer Sciences, 2018;26: 2088-2103.

[12] Açıkgöz, H. Üç Seviyeli D-STATKOM'un Tip-2 Bulanık Mantık Denetleyici ile Denetimi ve Performans Analizi. Kahramanmaraş Sütçü İmam Üniversitesi Mühendislik Bilimleri Dergisi, 2018;21(4): 346-357.

[13] Eswaran T, Suresh Kumar V. Particle swarm optimization (PSO)-based tuning technique for PI controller for management of a distributed static synchronous compensator (D-STATCOM) for improved dynamic response and power Quality. J Appl Res Technol, 2017;15(2):173-189.

[14] Liu F, Mei S, Lu Q, Ni Y, Wu FF, Yokoyama A. The nonlinear internal control of STATCOM: theory and application, Int J Electr Power Energy Syst, 2003; 25; 421-430.

[15] Dawood A. D-STATCOM modelling for voltage stability with fuzzy logic PI current controller. Int J Electr Power Energy Syst, 2016;76: 129-135.

[16] Coteli R, Dandil B, Ata F. Fuzzy-PI current controlled D-STATCOM. Gazi University Journal of Science, 2011; 24:9199. 
[17] Suryanarayana H, Mahesh KM. Fuzzy logic based supervision of dc link PI control in a DSTATCOM. In: IEEE 2008 India Conference; 11-13 December 2008; Kanpur, India: IEEE. pp. 1-6.

[18] Valderrábano A, Juan MR. D-STATCOM regulation by a fuzzy segmented PI controller. Electr Pow Syst Res 2010; 80: 707.

[19] Nagesh G, Mahesh KM, Manoj Kumar MV. SRF based current controller using PI and HC regulators for D-STATCOM with SPWM switching. Int J Electr Power Energy Syst, 2015;67: 87-100.

[20] Petitclair P, Bacha S, Ferrieux JP. Optimized linearization via feedback control law for a STATCOM. In: 32nd Industry Applications Conference; 5-9 October 1997; New Orleans, LA, USA. New York, NY, USA: IEEE. pp. 880-885.

[21] Petitclair P, Bacha S, Rognon JP. Averaged modelling and nonlinear control of an advanced static VAr compensator. In: IEEE 1996 Power Electronics Specialists Conference; 23-27 June 1996; Baveno, Italy. New York, NY, USA: IEEE. pp. 753-758.

[22] Zadeh LA. Fuzzy Sets. Inform Con, 1965; 8(3): 338-353.

[23] Gani A, Acikgoz H, Kececioglu OF, Sekkeli M. Fuzzy Logic Controller Design Based On Sugeno Inference Method For Nonlinear Inverted Pendulum Dynamical System. Sigma J Eng \& Nat Sci, 2017; 8(1):19-30

[24] Gunes M, Dogru N. Fuzzy control of brushless excitation system for steam turbogenerators. IEEE Trans Energy Convers. 2010;25(3):844-852.

[25] Acikgoz H, Kececioglu OF, Gani A, Yildiz C, Sekkeli M. Optimal Control and Analysis of Three Phase Electronic Power Transformers. Procedia - Social and Behavioral Sciences, 2015; 195: 2412-2420.

[26] Jan J. Tuning of fuzzy PID controllers. Denmark Tech. Report No 98-H871(fpid), 1998, pp.1-22. 